\title{
National Survey of Primary Care Physicians' Knowledge, Practices, and Perceptions of Prediabetes
}

\author{
Eva Tseng, $\mathrm{MD}^{1,2}$, Raquel C. Greer, $M D^{1,2}$, Paul O'Rourke, $\mathrm{MD}^{3}$, Hsin-Chieh Yeh, PhD ${ }^{1,2,4}$, \\ Maura M. McGuire, MD 1,5 , Ann L. Albright, PhD ${ }^{6}$, Jill A. Marsteller, PhD', \\ Jeanne M. Clark, $M D^{1,2,4}$, and Nisa M. Maruthur, $M D^{1,2,4}$

\begin{abstract}
'Division of General Internal Medicine, The Johns Hopkins University, Baltimore, MD, USA; ${ }^{2}$ Welch Center for Prevention, Epidemiology, \& Clinical Research, The Johns Hopkins University, Baltimore, MD, USA; ${ }^{3}$ Division of General Internal Medicine, Johns Hopkins Bayview Medical Center, Baltimore, MD, USA; ${ }^{4}$ Department of Epidemiology, The Johns Hopkins University Bloomberg School of Public Health, Baltimore, MD, USA; ${ }^{5}$ Johns Hopkins Community Physicians, Baltimore, MD, USA; ${ }^{6}$ Division of Diabetes Translation, Centers for Disease Control and Prevention, Atlanta, GA, USA; ${ }^{7}$ Department of Health Policy and Management, The Johns Hopkins University Bloomberg School of Public Health, Baltimore, MD, USA.
\end{abstract}

BACKGROUND: Despite strong evidence and national policy supporting type 2 diabetes prevention, little is known about type 2 diabetes prevention in the primary care setting.

OBJECTIVE: Our objective was to assess primary care physicians' knowledge and practice regarding perceived barriers and potential interventions to improving management of prediabetes.

DESIGN: Cross-sectional mailed survey.

PARTICIPANTS: Nationally representative random sample of US primary care physicians (PCPs) identified from the American Medical Association Physician Masterfile.

MAIN MEASURES: We assessed PCP knowledge, practice behaviors, and perceptions related to prediabetes. We performed chi-square and Fisher's exact tests to evaluate the association between PCP characteristics and the main survey outcomes.

KEY RESULTS: In total, 298 (33\%) eligible participants returned the survey. PCPs had limited knowledge of risk factors for prediabetes screening, laboratory diagnostic criteria for prediabetes, and management recommendations for patients with prediabetes. Only 36\% of PCPs refer patients to a diabetes prevention lifestyle change program as their initial management approach, while $43 \%$ discuss starting metformin for prediabetes. PCPs believed that barriers to type 2 diabetes prevention are both at the individual level (e.g., patients' lack of motivation) and at the system level (e.g., lack of weight loss resources). PCPs reported that increased access to and insurance coverage of type 2 diabetes prevention programs and coordination of referral of patients to these resources would facilitate type 2 diabetes preventive efforts.

CONCLUSIONS: Addressing gaps in PCP knowledge may improve the identification and management of people with prediabetes, but system-level changes are necessary to support type 2 diabetes prevention in the primary care setting.

KEY WORDS: prevention; survey research; primary care.

Received November 30, 2018

Revised April 1, 2019

Accepted June 21, 2019

Published online September 9, 2019
J Gen Intern Med 34(11):2475-81

DOI: $10.1007 /$ s11606-019-05245-7

(C) Society of General Internal Medicine 2019

\section{INTRODUCTION}

One in three US adults (84.1 million) has prediabetes and is at high risk for developing type 2 diabetes. ${ }^{1,2}$ Fortunately, a strong evidence base demonstrates that type 2 diabetes can be prevented or delayed through feasible lifestyle change interventions. ${ }^{3-5}$ Diabetes prevention has become part of US policy with the Centers for Disease Control and Prevention (CDC) establishing the National Diabetes Prevention Program (National DPP $)^{6}$; this program raises awareness about prediabetes and diabetes prevention, and provides an infrastructure for nationwide delivery of the diabetes prevention lifestyle change program shown to be effective in the DPP trial and subsequent translation studies. ${ }^{3}$ Starting April 2018, the Centers for Medicare \& Medicaid Services (CMS) began providing payment to $\mathrm{CDC}$-recognized organizations who become Medicare suppliers of the lifestyle change program, ${ }^{7}$ marking the first time that Medicare is covering a lifestyle intervention for primary prevention of a chronic disease.

Despite these advances in evidence and policy supporting diabetes prevention, $90 \%$ of individuals with prediabetes are unaware of their diagnosis, ${ }^{1}$ an unchanged statistic for the past decade. ${ }^{8} 9$ Primary care physicians (PCPs) play an essential role in diabetes prevention by diagnosing and managing prediabetes. However, analyses of the National Health and Nutrition Examination Survey and electronic health records indicate that most patients with prediabetes are not receiving evidence-based care from PCPs for diabetes prevention. ${ }^{10-13}$ Less is known about PCP knowledge about and practice behaviors around prediabetes. In a previous regional survey, we found significant gaps in PCP knowledge of prediabetes and underutilization of behavioral weight loss programs for prediabetes. ${ }^{14}$ The system in which physicians work may also limit their ability to provide the best evidence-based care, due to influences such as performance measures, insurance 
reimbursement, cultural expectations, and insufficient tools and limited staffing resources. ${ }^{15}$ Therefore, we conducted a survey evaluating PCP knowledge, management practices, and perceptions related to prediabetes.

\section{METHODS}

\section{Setting and Survey Design}

We surveyed a sample of 1000 PCPs in the USA randomly selected through the American Medical Association (AMA) Physician Masterfile, a nationally representative listing of all US physicians. ${ }^{16}$ This database includes individuals entering an accredited US medical school or international medical graduates entering an accredited US residency program. For this survey, eligible physicians included licensed general internists, family physicians, and general practitioners who had completed residency training.

We revised and adapted a survey instrument used in the previous regional survey. ${ }^{14}$ We based the survey domains on clinical practice recommendations for prediabetes care and existing literature ${ }^{12,13,17}$ and refined the survey instrument by piloting it among PCPs working in community practices $(n=7)$ using cognitive interviews to improve the clarity and interpretability of the questions. We mailed the survey and an unconditional incentive of $\$ 10$ in the first mailing to the randomly selected sample. Non-respondents received up to 2 additional mailings separated by 1-month intervals between October 2017 and January 2018. The survey included a link to an online version of the survey designed and administered through REDCap; respondents could complete the paper survey and return by mail or take the survey online.

\section{Survey Instrument Contents}

The survey evaluated the following: (1) knowledge of risk factors that should prompt prediabetes screening, laboratory criteria for diagnosing prediabetes, and recommendations for prediabetes management; (2) practice behaviors regarding prediabetes management; and (3) perceived barriers and potential interventions to improving prediabetes management. We used the American Diabetes Association (ADA) recommendations ${ }^{17}$ as it was the reported primary source used by PCPs in our regional study. ${ }^{14}$

Knowledge of Risk Factors, Laboratory Criteria, and Recommendations. The survey provided PCPs with a list of potential risk factors to select as ones that would prompt screening for prediabetes. ${ }^{18}$ We asked PCPs to circle the numeric values corresponding to the upper and lower limits of the laboratory criteria (fasting glucose and HbAlc) for diagnosing prediabetes and diabetes. PCPs were asked to identify what guidelines recommend as the initial management approach, minimum weight loss (\% body weight), and minimum physical activity (minutes/week) for patients with prediabetes.
Practice Behaviors for Prediabetes. We asked PCPs about their use of prediabetes screening tests (including fasting glucose, 2-h oral glucose tolerance test, and/or HbA1c), initial management approach, and intervals for repeat laboratory work and follow-up visits. We also asked them which recommendations they use for prediabetes screening (ADA, U.S. Preventive Services Task Force (USPSTF), American Association of Clinical Endocrinologists (AACE)).

Barriers and Interventions for Prediabetes Management. To evaluate perceptions regarding prediabetes, we used a 5-point Likert scale (strongly agree to strongly disagree) to assess PCP attitudes regarding lifestyle modification and metformin as interventions to reduce type 2 diabetes risk. We used a similar 5-point Likert scale to evaluate what PCPs perceive as patient barriers to lifestyle modification and metformin use (Table 2). We asked PCPs to select possible interventions for improving prediabetes management (Table 2).

Physician Characteristics. We asked PCPs about their average number of hours per week spent in outpatient clinical care, primary clinical setting, location of their primary practice (urban, suburban, or rural), insurance status of their patients, and their race/ethnicity. We obtained additional demographic data (year since completing residency, gender, age, type of primary care doctor) through the AMA Physician Masterfile for respondents of the second and third waves of survey mailings $(n=99)$. We were unable to match this information for respondents of the first wave due to an oversight where surveys were not labeled with an identification number and therefore the completed surveys could not be linked back to these demographic data for that wave.

\section{Statistical Analysis}

One research team member entered the survey data in REDCap while another compared the data entries with the original paper survey form and corrected any discrepancies. We conducted descriptive analyses to quantify survey responses related to the main outcomes. We performed chi-square and Fisher's exact (when $n<10$ in any cell) tests to determine whether PCP characteristics were associated with the main outcomes. For questions with a Likert scale, we dichotomized the answers by combining agree and strongly agree vs. neutral, disagree, and strongly disagree. Analyses were conducted using STATA 15.1 (College Station, TX). This study was exempted by the Johns Hopkins University School of Medicine Institutional Review Board.

\section{RESULTS}

\section{Sample}

Of 1000 mailed surveys, 13 were returned by the post office with no forwarding address and 99 were returned by ineligible 
Table 1 Demographics of Survey Respondents (Total $n=298$ )

\begin{tabular}{|c|c|}
\hline & $N(\%)$ \\
\hline \multicolumn{2}{|l|}{ Physician characteristics } \\
\hline \multicolumn{2}{|l|}{ Age* $(n=99)$} \\
\hline $30-39$ & $3(3.0)$ \\
\hline $40-49$ & $18(18.2)$ \\
\hline $50-59$ & $28(28.3)$ \\
\hline $60+$ & $50(50.5)$ \\
\hline Female gender* $(n=96)$ & $29(30.2)$ \\
\hline Hispanic ethnicity $(n=289)$ & $24(8.3)$ \\
\hline \multicolumn{2}{|l|}{ Race $(n=298)^{\dagger}$} \\
\hline American Indian & $2(0.7)$ \\
\hline Asian & $41(13.8)$ \\
\hline Black & $13(4.4)$ \\
\hline Hawaiian & $3(1.0)$ \\
\hline White & $222(74.5)$ \\
\hline Other & $13(4.4)$ \\
\hline \multicolumn{2}{|l|}{ Number of hours/week in outpatient } \\
\hline \multicolumn{2}{|l|}{ clinical care $(n=291)$} \\
\hline$<20$ & $21(7.2)$ \\
\hline $20-29$ & $43(14.8)$ \\
\hline $30-39$ & $129(44.3)$ \\
\hline $40+$ & $98(33.7)$ \\
\hline \multicolumn{2}{|l|}{ Type of primary care physician* $(n=99)$} \\
\hline Internal medicine & $27(27.3)$ \\
\hline Family medicine & $35(35.4)$ \\
\hline General practitioner & $37(37.4)$ \\
\hline \multicolumn{2}{|c|}{ Number of years since completing training* $(n=73)$} \\
\hline$<10$ years & $9(12.3)$ \\
\hline $10-19$ years & $19(26.0)$ \\
\hline $20-29$ years & $22(30.1)$ \\
\hline $30+$ years & $23(31.5)$ \\
\hline \multicolumn{2}{|l|}{ Practice characteristics } \\
\hline \multicolumn{2}{|l|}{ Practice setting $(n=292)$} \\
\hline Private solo or group practice & $181(62.0)$ \\
\hline Practice of outpatient department & $83(28.4)$ \\
\hline \multicolumn{2}{|c|}{ affiliated with hospital or large health entity } \\
\hline Health maintenance organization & $7(2.4)$ \\
\hline \multicolumn{2}{|l|}{ or other prepaid practice } \\
\hline Non-federal government clinic & $4(1.4)$ \\
\hline Federal government-operated clinic & $3(1.0)$ \\
\hline Community health center & $14(4.8)$ \\
\hline \multicolumn{2}{|l|}{ Practice location $(n=292)$} \\
\hline Urban & $91(31.2)$ \\
\hline Suburban & $123(42.1)$ \\
\hline Rural & $78(26.7)$ \\
\hline \multirow{2}{*}{\multicolumn{2}{|c|}{$\begin{array}{l}\text { Median reported insurance type, \% } \\
(\text { IOR })^{\ddagger}(n=248)\end{array}$}} \\
\hline & \\
\hline Private & $40(29-56)$ \\
\hline Medicare & $30(25-50)$ \\
\hline Medicaid & $15(7.5-30)$ \\
\hline Worker's compensation & $1(0-3)$ \\
\hline Self-pay & $2(3-10)$ \\
\hline No charge/charity & $4(1-5)$ \\
\hline
\end{tabular}

*Certain baseline characteristics only available for respondents of the second and third waves of mailings. Additionally, due to missing data for individual questions, not all totals for responses to survey items equal 298

†Adds up to $>100 \%$ because more than one answer could be selected $\neq$ Sum does not equal $100 \%$ because some physicians reported "other" insurance types

physicians (i.e., not primary care doctors); thus, we considered 888 to be eligible to complete the survey. We received 298 completed surveys resulting in a response rate of $33 \%$.

Table 1 displays the self-reported characteristics of survey respondents. The majority were $\geq 60$ years in age and in practice for over 20 years. Most respondents were nonHispanic (92\%) and white (75\%). Internal medicine, family medicine, and general practitioners were represented equally. Practice locations were $31 \%$ urban, $42 \%$ suburban, and $27 \%$ rural. Their patients mostly had private insurance (median
40\%, IQR 29-56\%), Medicare (median 30\%, IQR 25-50\%), and/or Medicaid (median 15\%, IQR 7.5-30\%).

Risk Factors for Prediabetes Screening. On average, physicians selected 10 of 15 correct risk factors for prediabetes screening. Fifteen percent of physicians correctly identified all 15 risk factors. The least commonly identified risk factors were African American race (44\%), Native American race (41\%), Latino ethnicity (38\%), Asian race (27\%), and $\mathrm{BMI} \geq 23 \mathrm{~kg} / \mathrm{m}^{2}$ for Asian Americans (27\%). PCPs who had graduated $>20$ years ago were more likely to identify all risk factors vs. younger graduates $(n=11 / 45$ $(24.4 \%)$ vs. $n=1 / 28(3.6 \%), p=0.02)$.

Laboratory Criteria for Diagnosing Prediabetes. Figure 1 shows the percentage of PCPs selecting the correct values of fasting glucose and $\mathrm{HbAlc}$ for identifying diabetes and prediabetes. Roughly $50 \%$ of PCPs selected the correct criteria for diabetes with lower rates for prediabetes $(42 \%$ selected correct range for fasting glucose and $31 \%$ for HbAlc). Forty percent of PCPs selected the lower limit cutoff of $\mathrm{HbAlc}$ for prediabetes as being higher than the recommended cutoff of $5.7 \%$, and $25 \%$ of PCPs selected the upper limit cutoff as being higher than the recommended cutoff of $6.4 \%$ (Fig. 1).

Knowledge of Recommendations for Prediabetes Management. Table 2 shows that most PCPs (70\%) selected counseling on diet and physical activity while some (30\%) selected referral to a diabetes prevention lifestyle change program as the recommended "initial management approach" for prediabetes. Only $8 \%$ of PCPs selected $7 \%$ as the minimum weight loss recommendation (answer options included $1-20 \%$ in $1 \%$ increments), the goal suggested by the ADA (Table 1). Twenty percent of PCPs selected 5\% weight loss, the lower value required by the National DPP, while $41 \%$ selected $10 \%$ weight loss; one quarter answered "Do not know." Forty-one percent chose 150 min per week as the recommended minimum amount of physical activity (answer options included 10-200 min in 10-min increments) with 13\% reporting "Do not know." Compared with younger graduates, PCPs who graduated $>10$ years ago were less likely to know the correct recommendation for physical activity $(n=8 / 9$ $(88.9 \%)$ vs. $n=26 / 61(42.6 \%), p=0.01)$.

Over $20 \%$ of physicians reported not using any specific recommendations for the screening and management of prediabetes (data not shown). The remainder reported using the ADA (57\%), USPSTF (29\%), and AACE (14\%) recommendations. PCPs who used the ADA recommendations were more likely to select referral to a diabetes prevention lifestyle change program ( $n=58 / 170(34.1 \%)$ vs. $n=30 / 128(23.4 \%)$, $p=0.05)$ as the recommended initial management approach.

Practice Behaviors for Prediabetes. Physicians reported primarily using a fasting blood glucose $(83 \%)$ or $\mathrm{HbAlc}(87 \%)$ for prediabetes screening although some also reported using a 

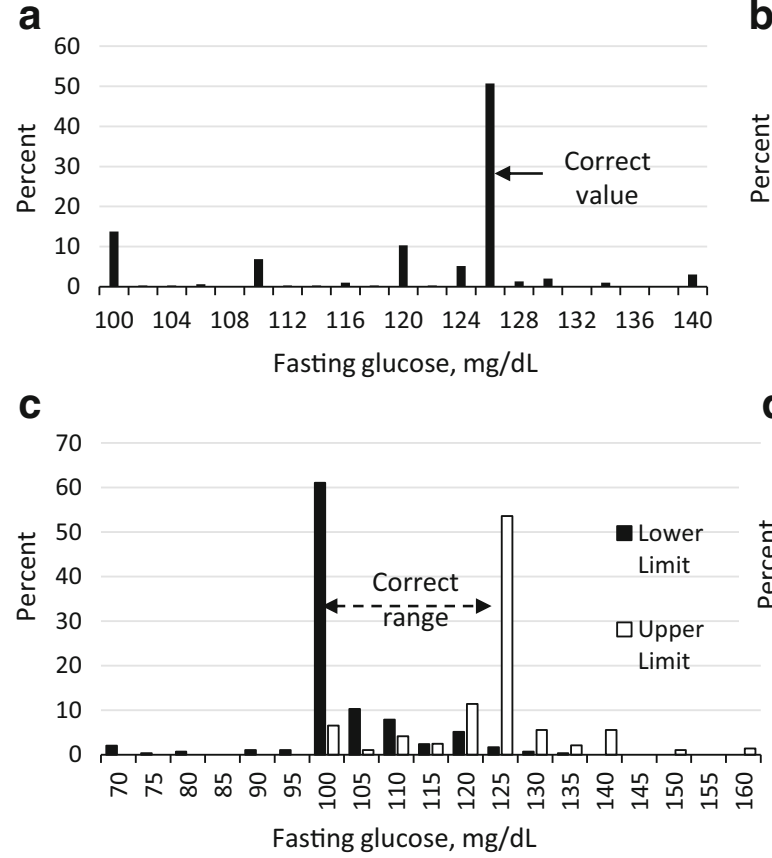

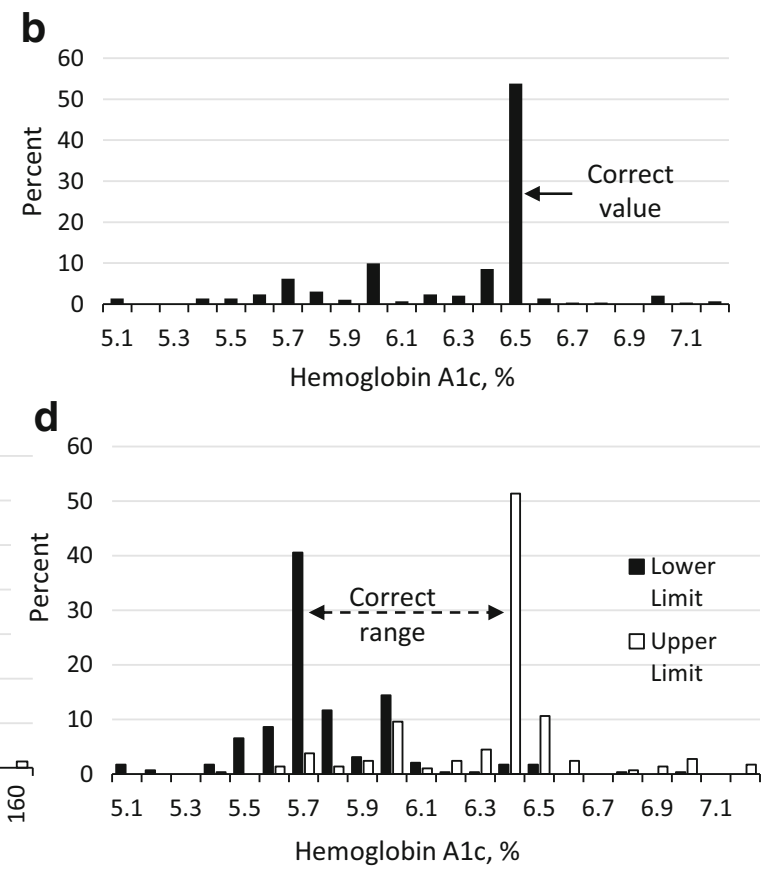

Figure 1 Selected values for the diagnostic criteria for a diabetes based on fasting glucose, b diabetes based on hemoglobin A1c, c prediabetes based on fasting glucose, and d prediabetes based on hemoglobin A1c.

non-fasting blood glucose $(27 \%)$ or 2-h oral glucose tolerance test $(8 \%)$ (total $>100 \%$ since more than 1 answer could be selected). As their initial management strategy, PCPs most commonly reported counseling on diet changes and physical activity (93\%) (Table 2); only 36\% referred patients to a diabetes prevention lifestyle change program, and $43 \%$ discussed starting metformin for prediabetes. PCPs who graduated $>10$ years ago were less likely to refer patients to a diabetes prevention lifestyle change program compared with younger graduates $(n=19 / 62$ (30.7\%) vs. $n=7 / 9$ (77.8\%), $p=0.01$ ). PCPs reported close follow-up of patients with prediabetes for repeat laboratory work and follow-up visits in the 3-6-month timeframe (Table 2).

Fifty-seven percent of PCPs reported prescribing metformin for up to $25 \%$ of their patients while $15 \%$ of physicians reported never prescribing metformin (Table 2). Physicians were more likely to prescribe metformin if a patient does not respond to lifestyle change (64\%), has a BMI $\geq 35 \mathrm{~kg} / \mathrm{m}^{2}$ $(59 \%)$, has an $\mathrm{HbA} 1 \mathrm{c}>6 \%(59 \%)$, or has a family history of diabetes $(45 \%)$.

\section{Patient and System Barriers and Interventions to Improving Prediabetes Management. Most physicians agreed or strongly agreed $(89 \%)$ that patients with prediabetes progress to type 2 diabetes more quickly than those with normoglycemia and that lifestyle modification reduces that risk of progression (93\%). Fewer physicians (79\%) agreed that metformin can reduce the risk of diabetes in their patients with prediabetes. PCPs who disagreed about metformin's ability to reduce the progression to diabetes were more likely to report never prescribing metformin (24/ $223(10.8 \%)$ vs. $n=20 / 59(33.9 \%), p<0.001)$.}

Physicians felt most strongly that important barriers to lifestyle modification for their patients include lack of motivation $(94 \%)$, limited or lack of success with prior lifestyle modification (79\%), and stress in their life (70\%) (Table 2). PCPs practicing in urban areas $(n=31 / 90(34.4 \%)$ vs. $n=45 /$ 195 (23.1\%), $p=0.04$ ), and PCPs reporting $\geq 25 \%$ of their patients are insured by Medicaid $(n=24 / 63(38.1 \%)$ vs. $29 /$ $124(23.4 \%), p=0.04)$ were more likely to report limited access to grocery stores and healthy food options as important barriers for their patients.

Regarding potential interventions for improving prediabetes management, PCPs reported that increased availability of (90\%) and insurance coverage for (90\%) diabetes prevention programs, improved nutrition resources $(88 \%)$ and access to weight loss programs (86\%), and coordination of patients' referral to lifestyle change programs $(84 \%)$ would be helpful (Table 2).

Physicians noted patients' dislike of taking medications $(87 \%)$, anticipated poor adherence $(78 \%)$, and potential side effects $(74 \%)$ as influential barriers to metformin use for diabetes prevention (Table 2).

\section{DISCUSSION}

In this national survey, we found substantial gaps in PCP knowledge of risk factors, diagnostic criteria, and evidence-based recommendations for prediabetes. Importantly, PCPs identified both patient- and system-level barriers to and facilitators for diabetes prevention in primary care. To our knowledge, this is the first national survey to evaluate PCP knowledge and practices related 
Table 2 Reported Knowledge, Practices, and Perceptions of Barriers/Interventions for Prediabetes

\begin{tabular}{|c|c|}
\hline & $N(\%)$ \\
\hline \multicolumn{2}{|l|}{$\begin{array}{l}\text { Knowledge of recommendations for management of prediabetes } \\
\text { Initial management approach* }\end{array}$} \\
\hline Refer to diabetes prevention lifestyle change program & $88(29.7)$ \\
\hline Counseling on diet changes and physical activity & $\begin{array}{l}209 \\
(70.1)\end{array}$ \\
\hline Refer to nutritionist & $50(16.8)$ \\
\hline Discuss starting metformin & $53(17.8)$ \\
\hline Refer to bariatric surgery & $9(3.0)$ \\
\hline $150 \mathrm{~min} /$ week of physical activity & $\begin{array}{l}120 \\
(41.0)\end{array}$ \\
\hline $7 \%$ body weight loss & $22(7.6)$ \\
\hline \multirow{2}{*}{\multicolumn{2}{|c|}{$\begin{array}{l}\text { Practice behaviors } \\
\text { Initial management app }\end{array}$}} \\
\hline & \\
\hline $\begin{array}{l}\text { Refer to diabetes prevention lifestyle } \\
\text { chanoe nrooram }\end{array}$ & 107 \\
\hline $\begin{array}{l}\text { change program } \\
\text { Counseling on diet changes and physical activity }\end{array}$ & $\begin{array}{l}(35.9) \\
276 \\
(92.6)\end{array}$ \\
\hline Refer to nutritionist & $\begin{array}{l}123 \\
(41.3)\end{array}$ \\
\hline Discuss starting metformin & $\begin{array}{l}128 \\
(43.0)\end{array}$ \\
\hline Refer to bariatric surgery & $30(10.1)$ \\
\hline \multicolumn{2}{|l|}{ Repeat lab work } \\
\hline 3 months & $\begin{array}{l}126 \\
(42.9)\end{array}$ \\
\hline 6 months & $\begin{array}{l}133 \\
(45.2)\end{array}$ \\
\hline 1 year & $24(8.2)$ \\
\hline \multicolumn{2}{|l|}{ Return for follow-up clinic visit } \\
\hline 3 months & $\begin{array}{l}128 \\
(43.5)\end{array}$ \\
\hline 6 months & $\begin{array}{l}124 \\
(42.2)\end{array}$ \\
\hline 1 year & $16(5.4)$ \\
\hline \multicolumn{2}{|l|}{$\begin{array}{l}\text { Patients with prediabetes you have } \\
\text { prescribed metformin }\end{array}$} \\
\hline $0 \%$ & $44(15.2)$ \\
\hline $1-5 \%$ & $78(27.0)$ \\
\hline$>5-25 \%$ & $88(30.5)$ \\
\hline$>25-50 \%$ & $45(15.6)$ \\
\hline$>50-75 \%$ & $24(8.3)$ \\
\hline$>75 \%$ & $10(3.5)$ \\
\hline \multicolumn{2}{|l|}{$\begin{array}{l}\text { Patient and system barriers to lifestyle modification } \\
\text { (strongly agree or agree) }\end{array}$} \\
\hline Patient's lack of motivation & $\begin{array}{l}275 \\
(93.9)\end{array}$ \\
\hline Patient's lack of time & $\begin{array}{l}201 \\
(69.1)\end{array}$ \\
\hline $\begin{array}{l}\text { Patient's lack of knowledge of what to do for lifestyle } \\
\text { change }\end{array}$ & $\begin{array}{l}199 \\
(69.1)\end{array}$ \\
\hline Patient's physical limitation in doing activity & $\begin{array}{l}158 \\
(54.1)\end{array}$ \\
\hline Stress in patient's life & $\begin{array}{l}204 \\
(69.9)\end{array}$ \\
\hline $\begin{array}{l}\text { Limited or lack of success with prior lifestyle } \\
\text { modification }\end{array}$ & $\begin{array}{l}230 \\
(79.3)\end{array}$ \\
\hline Lack of weight loss and/or nutrition resources for patient & $\begin{array}{l}176 \\
(60.7)\end{array}$ \\
\hline Patients do not think it is important to make these changes & $\begin{array}{l}168 \\
(57.7)\end{array}$ \\
\hline Financial limitations & $\begin{array}{l}130 \\
(44.7)\end{array}$ \\
\hline $\begin{array}{l}\text { Lack of safe community spaces for engaging in physical } \\
\text { activity }\end{array}$ & $67(22.9)$ \\
\hline Limited access to grocery stores and healthy food options & $77(26.5)$ \\
\hline $\begin{array}{l}\text { Patient and system barriers to metformin use } \\
\text { (strongly agree or agree) }\end{array}$ & \\
\hline Patients dislike taking medications & $\begin{array}{l}254 \\
(87.0)\end{array}$ \\
\hline Medication cost to patient & $92(31.6)$ \\
\hline Poor patient adherence & $\begin{array}{l}227 \\
(77.5)\end{array}$ \\
\hline
\end{tabular}

Table 2. (continued)

\begin{tabular}{ll}
\hline \hline & $N(\%)$ \\
\hline Potential side effects & 216 \\
& $(74.0)$ \\
Contraindication such as chronic kidney disease & 159 \\
& $(54.4)$ \\
Physicians' lack of awareness of clinical guidelines for & 162 \\
metformin use & $(55.3)$ \\
Physician's belief that patients can improve with lifestyle & 203 \\
change & $(68.8)$ \\
Lack of FDA approval for metformin use in prediabetes & 109 \\
& $(37.2)$ \\
Interventions to improving management of prediabetes & \\
(strongly agree or agree) & 226 \\
More time for doctors to counsel patients & $(76.9)$ \\
Patient counseling by nurse & 218 \\
& $(74.7)$ \\
Increased physician education about prediabetes & 220 \\
Educational materials for patients & $(75.3)$ \\
& 221 \\
Increased availability of Diabetes Prevention Programs & 265 \\
& $(90.1)$ \\
Increased insurance coverage of Diabetes Prevention & 263 \\
Programs & $(89.5)$ \\
Improved nutrition resources for patients & 258 \\
& $(87.8)$ \\
Improved access to weight loss programs & 250 \\
& $(85.9)$ \\
Coordinating patient's referral to lifestyle change program & 244 \\
Clinical decision support tools & $(83.6)$ \\
& 190 \\
Physician incentives & $(64.6)$ \\
& 129 \\
& $(43.7)$ \\
\hline
\end{tabular}

*Adds up to $>100 \%$ because more than one answer could be selected

to prediabetes. Understanding prediabetes management in primary care is important as the national landscape for type 2 diabetes prevention is evolving rapidly.

Inadequate PCP knowledge of risk factors, diagnostic criteria, and screening tests likely lead to underscreening of at-risk individuals and low rates of identification of patients with prediabetes. National CDC data support this finding as nearly $90 \%$ of persons with laboratory values consistent with prediabetes are unaware of their status. ${ }^{1}$ Our results also suggest that $25 \%$ of PCPs may be identifying people as having prediabetes when they actually have diabetes which could lead to delays in diabetes-specific preventive care. One-fourth of PCPs reported using a non-fasting glucose for prediabetes screening even though no such diagnostic criteria exist.

We also found low knowledge and implementation of evidence-based recommendations for prediabetes, specifically the referral of patients to diabetes prevention lifestyle programs. PCPs most commonly recommend $10 \%$ weight loss to their patients with prediabetes, but evidence suggests that lower thresholds (5-7\%) are sufficient for achieving clinical benefits. ${ }^{17,19,20}$ Knowledge of this lower weight loss target is essential for providing patients achievable goals. Competing demands, including the need to meet quality metrics and maintain patient volume, may limit providers' ability to stay current with evidence for prediabetes; therefore, in addition to systematic education efforts for PCPs, expanding other team 
members' roles and clinical decision support may improve prediabetes identification and management.

Consistent with prior literature, ${ }^{21,}{ }^{22}$ PCPs reported significant patient barriers to managing prediabetes, including a lack of motivation. Identifying and discussing the diagnosis of prediabetes with a patient may be a salient moment for PCPs to motivate patients to make lifestyle changes; prior studies have demonstrated the important role that PCPs play in motivating patients to make lifestyle change. ${ }^{23-26}$ PCPs identified other patient barriers to lifestyle change including stress, limited time, and constrained resources; the diabetes prevention lifestyle change program is grounded in effective behavioral intervention methodology focusing on incremental changes in health behaviors and these important life factors. ${ }^{19}$

PCPs identified patients' dislike of taking medications, poor adherence, and potential side effects as barriers to metformin use. A recent study showed that patients with diabetes risk factors felt that lifestyle intervention and metformin were both acceptable treatment options for prediabetes ${ }^{39}$ with some wanting to combine modalities. Therefore, physicians' perceived barriers, including patients' reluctance to take medication, may be incorrect. Our results showing lower PCP knowledge about metformin's effectiveness in diabetes prevention may influence practice behaviors around prescribing metformin. Recent studies show that $<1 \%$ of patients with prediabetes are on metformin. ${ }^{12,13,27}$

PCPs identified a lack of weight loss resources for patients as an important system-level barrier. The number of CDCrecognized organizations delivering the National DPP lifestyle change program is growing rapidly and is now available in every state, ${ }^{28}$ but may not be widely available and accessible. There is ongoing effort by multiple stakeholders to increase the availability of the National DPP lifestyle change program. The AMA is working closely with practices and health systems to deliver these programs to their patients or to help connect them to local CDC-recognized organizations. ${ }^{29}$ Online programs may help address accessibility issues. If local programs are unavailable, resources like registered dietitians can be utilized although may not be covered by all insurers, and educational materials (e.g., through the National Diabetes Education Program) can be provided to at-risk individuals. ${ }^{30}$, ${ }^{31}$ Other non-CDC-recognized diabetes prevention lifestyle programs may be available, but they may not have the longterm evidence or outcomes that CDC-recognized programs have and may not be covered by insurance.

Most PCPs strongly believe that system-level interventions for improving the management of prediabetes should include increasing insurance coverage of and coordinated referral to National DPP lifestyle change programs. Coverage of these programs (in-person and online) is expanding, beginning with commercial insurers and now with CMS. ${ }^{7}$ Increasing physician education about the evidence behind diabetes prevention and having a direct referral mechanism for nearby National DPP lifestyle change programs would likely improve referral rates. Ultimately, this requires integration of community-based National DPP lifestyle change programs into electronic referral workflows. Other improvements such as clinical decision support tools have been shown to improve processes of care for diabetes and other illnesses ${ }^{32,33}$ and may be effective for the diagnosis and management of prediabetes.

Strengths of this study include its national coverage of PCPs in a variety of practice settings and the comprehensive nature of the survey. The major limitation to this study is the relatively low response rate which may limit the generalizability of our results; however, our response rate is comparable to other surveys of the AMA Masterfile sample to understand PCP knowledge, attitudes, and practices. ${ }^{34,} 35$ Respondents were similar to the national PCP population for most demographic characteristics, including gender, race/ethnicity, and practice setting. ${ }^{36,37}$ However, respondents were generally older than the national PCP population (62\% vs. $25 \%$ were aged 60 and older). ${ }^{37}$ We used the term "diabetes prevention lifestyle program" when asking PCPs about management approaches to avoid leading respondents in their responses, but PCPs may have selected this management option without meaning the structured behavioral weight loss program in the DPP study. Therefore, our estimate that one-third of PCPs recommend their patients with prediabetes to a diabetes prevention lifestyle program may overestimate the referral rate. There may be recall bias (unmotivated misreporting) regarding physician practices ${ }^{38}$ and social desirability bias (motivated misreporting in a socially desirable direction) in responding to questions about perceived barriers and practices, leading to more positive agreement about the importance of prediabetes. ${ }^{38}$

Our national survey findings suggest that gaps in PCP knowledge contribute to the inadequate diagnosis of prediabetes and referral to diabetes prevention interventions. In addition to provider education, addressing system-level barriers to type 2 diabetes prevention is important and will require partnerships with community resources and leveraging of health information technology. PCPs play a critical role in identifying and treating the one in three adults with prediabetes. As type 2 diabetes prevention grows through dissemination of evidence-based interventions, increased engagement of PCPs is the next step to addressing the diabetes epidemic.

Acknowledgments: The authors thank Mr. Paul Sharrett for his assistance with the survey mailings and data entry.

Corresponding Author: Eva Tseng, MD; Division of General Internal Medicine The Johns Hopkins University, Baltimore, MD, USA (e-mail: etseng3@jhmi.edu).

Funders Johns Hopkins Primary Care Consortium Grant

\section{Compliance with Ethical Standards:}

This study was exempted by the Johns Hopkins University School of Medicine Institutional Review Board. 
Conflict of Interest: The authors declare that they do not have a conflict of interest.

Disclaimer: The findings and conclusions in this report are those of the authors and do not necessarily represent the official position of the Centers for Disease Control and Prevention.

\section{REFERENCES}

1. Centers for Disease Control and Prevention. National Diabetes Statistics Report, 2017. Atlanta, GA: Centers for Disease Control and Prevention, US Department of Health and Human Services; 2017.

2. Tabak AG, Herder C, Rathmann W, Brunner EJ, Kivimaki M. Prediabetes: a high-risk state for diabetes development. Lancet 2012;379(9833):2279-90.

3. Knowler WC, Barrett-Connor E, Fowler SE, Hamman RF, Lachin JM Walker EA, et al. Reduction in the incidence of type 2 diabetes with lifestyle intervention or metformin. N Engl J Med 2002;346(6):393-403.

4. Pan XR, Li GW, Hu YH, Wang JX, Yang WY, An ZX, et al. Effects of diet and exercise in preventing NIDDM in people with impaired glucose tolerance. The Da Qing IGT and Diabetes Study. Diabetes Care 1997;20(4):537-44

5. Balk EM, Earley A, Raman G, Avendano EA, Pittas AG, Remington PL Combined Diet and Physical Activity Promotion Programs to Prevent Type 2 Diabetes Among Persons at Increased Risk: A Systematic Review for the Community Preventive Services Task Force. Ann Intern Med 2015;163(6):437-51.

6. Albright A. Diabetes Prevention and Management: The Thrill Is Not Gone. Diabetes Spectr 2014;27(1):63-8.

7. Medicare Diabetes Prevention Program (MDPP) Expanded Model: Centers for Medicare \& Medicaid Services; 2019 [cited 2019 April 23]. Available from: https://innovation.cms.gov/initiatives/medicare-diabetes-prevention-program/.

8. Centers for Disease Control and Prevention. Diabetes Report Card 2010 Atlanta, GA: Centers for Disease Control and Prevention, US Department of Health and Human Services; 2012.

9. Centers for Disease Control and Prevention. Diabetes Report Card 2014 Atlanta, GA: Centers for Disease Control and Prevention, US Department of Health and Human Services; 2015

10. Rhee MK, Herrick K, Ziemer DC, Vaccarino V, Weintraub WS, Narayan KM, et al. Many Americans have pre-diabetes and should be considered for metformin therapy. Diabetes Care 2010;33(1):49-54.

11. Karve A, Hayward RA. Prevalence, diagnosis, and treatment of impaired fasting glucose and impaired glucose tolerance in nondiabetic U.S. adults. Diabetes Care 2010;33(11):2355-9.

12. Schmittdiel JA, Adams SR, Segal J, Griffin MR, Roumie CL, Ohnsorg $\mathbf{K}$, et al. Novel use and utility of integrated electronic health records to assess rates of prediabetes recognition and treatment: brief report from an integrated electronic health records pilot study. Diabetes Care 2014;37(2):565-8.

13. Moin T, Li J, Duru OK, Ettner S, Turk N, Keckhafer A, et al. Metformin Prescription for Insured Adults With Prediabetes From 2010 to 2012: A Retrospective Cohort Study. Ann Intern Med 2015;162(8):542-8.

14. Tseng E, Greer RC, O'Rourke P, Yeh HC, McGuire MM, Clark JM, et al. Survey of primary care providers' knowledge of screening for, diagnosing and managing prediabetes. J Gen Intern Med 2017;32(11):1172-1178.

15. Chan WV, Pearson TA, Bennett GC, Cushman WC, Gaziano TA Gorman PN, et al. ACC/AHA Special Report: Clinical practice Guideline Implementation Science Work Group: A Report of the American College of Cardiology/American Heart Association Task Force on Clinical Practice Guidelines. J Am Coll Cardiol 2017;69(8):1076-1092.

16. AMA Physician Masterfile: American Medical Association; 2018 [cited 2018 March 20]. Available from: https://www.ama-assn.org/life-career/ ama-physician-masterfile.

17. American Diabetes Association. Prevention or Delay of Type 2 Diabetes. Diabetes Care 2017;40(Suppl 1):S44-S7.

18. American Diabetes Association. Classification and diagnosis of diabetes. Diabetes Care 2018;Suppl 1:S13-S27.
19. National Diabetes Prevention Program: Curricula and Handouts: Centers for Disease Control and Prevention; 2018 [cited 2019 April 23]. Available from: https://www.cdc.gov/diabetes/prevention/lifestyle-program/curriculum.html.

20. Maruthur NM, Ma Y, Delahanty LM, Nelson JA, Aroda V, White NH, et al. Early response to preventive strategies in the Diabetes Prevention Program. J Gen Intern Med 2013;28(12): 1629-36.

21. Kandula NR, Moran MR, Tang JW, O'Brien MJ. Preventing Diabetes in Primary Care: Providers' Perspectives About Diagnosing and Treating Prediabetes. Clin Diabetes 2018;36(1):59-66.

22. Mainous AG, 3rd, Tanner RJ, Baker R. Prediabetes Diagnosis and Treatment in Primary Care. J Am Board Fam Med 2016;29(2):283-5.

23. Jay M, Gillespie C, Schlair S, Sherman S, Kalet A. Physicians' use of the 5As in counseling obese patients: is the quality of counseling associated with patients' motivation and intention to lose weight? BMC Health Serv Res 2010;10:159.

24. Huang J, Yu H, Marin E, Brock S, Carden D, Davis T. Physicians' weight loss counseling in two public hospital primary care clinics. Acad Med 2004;79(2): 156-61.

25. Post RE, Mainous AG, 3rd, Gregorie SH, Knoll ME, Diaz VA, Saxena SK. The influence of physician acknowledgment of patients' weight status on patient perceptions of overweight and obesity in the United States. Arch Intern Med 2011;171(4):316-21.

26. Rose SA, Poynter PS, Anderson JW, Noar SM, Conigliaro J. Physician weight loss advice and patient weight loss behavior change: a literature review and meta-analysis of survey data. Int J Obes 2013:37(1):118-28.

27. Tseng E, Yeh HC, Maruthur NM. Metformin Use in Prediabetes among U.S. Adults, 2005-2012. Diabetes Care 2017;40(7):887-93.

28. Centers for Disease Control and Prevention. National Diabetes Prevention Program. 2018; [cited 2019 April 23]. Available from: https://www.cdc. gov/diabetes/prevention/index.html

29. American Medical Association. Prevent Diabetes STAT. 2019; [cited 2019 April 23]. Available from: https://preventdiabetesstat.org/index.html

30. National Institute of Diabetes and Digestive and Kidney Diseases and Centers for Disease Control and Prevention. National Diabetes Education Program 2018; [cited 2019 April 23]. Available from: https://www.niddk. nih.gov/health-information/communication-programs/ndep

31. Centers for Disease Control and Prevention. National Diabetes Education Program. 2018; [cited 2019 April 23]. Available from: https://www.cdc. gov/diabetes/ndep/index.html

32. Chaudhry B, Wang J, Wu S, Maglione M, Mojica W, Roth E, et al Systematic review: impact of health information technology on quality, efficiency, and costs of medical care. Ann Intern Med 2006;144(10):74252.

33. Meigs JB, Cagliero E, Dubey A, Murphy-Sheehy P, Gildesgame C Chueh $\mathbf{H}$, et al. A controlled trial of web-based diabetes disease management: the $\mathrm{MGH}$ diabetes primary care improvement project. Diabetes Care 2003;26(3):750-7.

34. Raz DJ, Wu GX, Consunji M, Nelson R, Sun C, Erhunmwunsee L, et al. Perceptions and Utilization of Lung Cancer Screening Among Primary Care Physicians. J Thorac Oncol 2016;11(11):1856-62.

35. Venkataramani M, Cheng TL, Solomon BS, Pollack CE. Addressing Parental Health in Pediatrics: Physician Perceptions of Relevance and Responsibility. Clin Pediatr (Phila) 2017;56(10):953-8.

36. Xierali IM, Nivet MA. The racial and ethnic composition and distribution of primary care physicians. J Health Care Poor Underserved 2018;29(1):556-570.

37. Petterson S, McNellis R, Klink K, Meyers D, Bazemore A. The State of Primary Care in the United States: A Chartbook of Facts and Statistics. 2018

38. Wright JD, Marsden PV. Handbook of Survey Research. 2nd ed. San Diego, CA: Elsevier; 2010.

39. O'Brien MJ, Moran MR, Tang JW, Vargas MC, Talen M, Zimmermann $\mathbf{L}$, et al. Patient Perceptions About Prediabetes and Preferences for Diabetes Prevention. Diabetes Educ 2016;42(6):667-77.

Publisher's Note Springer Nature remains neutral with regard to jurisdictional claims in published maps and institutional affiliations. 